\title{
THE OPTIMAL SIZE OF CASH BALANCE UNDER LEARNING CURVE EFFECTS
}

\author{
Jianmin Feng, Shenzhen University, Shenzhen, Guangdong, P.R.China
}

\author{
dx.doi.org/10.18374/EJBR-13-1.2
}

\begin{abstract}
Based on learning curve theory, trading cost is decreasing with increasing of accumulative finance experience related to transferring between cash and securities in cash management process. Learning curve effect will happen when a company has much more finance experience with the trading experience, trading knowledge and trading Volume. This paper constructs the model of optimal size of cash under learning curve effects in cash balance decision process.
\end{abstract}

Keywords: optimal size of cash, trading costs, opportunity costs, learning curve effects 